\title{
及-Catenin Protein and Its Association with Helicobacter Pylori as A Possible Marker for Gastric Cancer
}

\author{
Mustafa K. Al-Bayaty ${ }^{1, *}$, Salma A. Abass ${ }^{1}$ and Mohammed F. Al-Marjani ${ }^{2}$ \\ ${ }^{1}$ Department of Chemistry, College of Science, Mustansiriyah University, Baghdad-Iraq. \\ ${ }^{2}$ Department of Biology, College of Science, Mustansiriyah University, Baghdad-Iraq. \\ *Corresponding author: mustafaalbayaty42@gmail.com
}

\begin{abstract}
Gastric cancer is still the main health threat being the third leading cause of deaths from cancers in the world, the major risk behind this disease is that it remains asymptomatic in the early stages and in $(97 \%)$ cases it metastasizes to other organs. Gastric cancer is a multifactorial disease with Helicobacter pylori ( $H$. pylori) being the major risk factor, however, patients with gastritis, especially atrophic gastritis and gastric ulcer have been shown to be at an increased risk for developing gastric cancer. In this research, serum $\beta$-catenin, carcinoembryonic antigen (CEA) and carbohydrate antigen 19-9 (CA 19-9) were measured in patients diagnosed with gastric cancer, gastric ulcer and gastritis and also in healthy volunteers. Infection with Helicobacter pylori ( $H$. pylori) was diagnosed by histological test, rapid urease test (RUT) and by serological tests which included IgG and IgA antibodies. The results showed that there was a large significant increase in the levels of serum $\beta$-catenin in patients with gastric cancer compared to the control group as well as to the gastritis and gastric ulcer patients. A significant increase was also seen in gastric ulcer and gastritis patients when compared to the control group. In addition, a significant increase was seen in $\beta$-catenin serum levels in patients with gastric cancer and gastric ulcer infected with $H$. pylori compared to the uninfected gastric cancer and gastric ulcer patients. A non-significant change was observed in the levels of CEA and CA 19-9 in all the patients compared to the control group. The results of this study suggest that $\beta$-catenin can serve as a potential biomarker for the diagnosis of gastric cancer and that $H$. pylori has a significant effect on the levels of this protein.
\end{abstract}

[DOI: $10.22401 /$ ANJS.22.3.06]

Keywords: Serum $\beta$-catenin, gastric cancer, Gastric ulcer, Gastritis, Helicobacter pylori.

\section{Introduction}

Stomach cancer is a serious threat to global health as it is the world's third leading cause of death from cancer [1,2]. Gastric cancer is divided into two subtypes according to the Lauren classification; the adenocarcinoma of the intestinal type and the adenocarcinoma of the diffuse type [3]. Gastric cancer etiology is multifactorial, but it is attributed to $H$. pylori infection in more than $80 \%$ of cases. Furthermore, genetics, lifestyle, diet and other factors contribute to carcinogenesis of the stomach [4]. H. pylori infects the stomach and leads to gastritis, peptic ulcer disease and also causes gastric cancers [5-8].

$\beta$-catenin is an important constituent of the adherens junctions (AJs). Imbalance in $\beta$ catenin's structural and signaling properties usually results in cancer-related disease and deregulated growth [9]. $\beta$-catenin binds ECadherin's intracellular cytoplasmic domain building the key component of AJs. Moreover, $\beta$-catenin binds the complex of cadherincatenin to the cytoskeleton of actin filaments. The functions of $\mathrm{AJs}$ include intracellular signaling, cell-cell adhesion, actin cytoskeleton local control, and junction disassembly [10]. The integrity of the AJs is vital for inhibiting the motility of individual cells [11]. Loss of this stability is vital to cancer initiation and progression.

$\beta$-catenin is also a transcriptional regulator in the wingless (Wnt) signaling pathway [12]. In the absence of Wnt ligands, cytoplasmic $\beta$ catenin is bound by the destruction complex, in contrast, when the secreted Wnt ligands bind to their receptor complex, the dissociation of the destruction complex occurs and this event prevents the phosphorylation and subsequent degradation of $\beta$-catenin, which accumulates in the cytoplasm and translocates to the nucleus [13]. Gastric tissue expression of $\beta$-catenin was estimated in many previous studies and have been linked to gastric cancer 
development [14] and apart from accumulation of $\beta$-catenin expression in cytoplasm or nuclear translocation, $\beta$-catenin levels can be detected in human serum and also have been reported to correlate with several disease progression, including hepatitis $\mathrm{C}$-associated hepatocellular carcinoma, type 2 diabetes mellitus, postmenopausal osteoporosis and these studies reported that $\beta$-catenin levels were elevated in the sera of patients compared to their controls [15-18]. However, through intensive search of the literature, only one study could be found regarding $\beta$-catenin serum levels in gastric cancer patients, in this study Weihua et al. established serum biomarker panels for the diagnosis of gastric cancer in 228 gastric cancer patients and 190 controls, their results reported that $\beta$-catenin serum levels were significantly increased in gastric cancer patients compared to the healthy controls [19].

Most of the gastric cancer cases arise from precancerous lesions starting from chronic inflammation, through gastritis, atrophic gastritis and finally to adenocarcinoma, it can be concluded that the measurement of $\beta$ catenin could give some information regarding the integrity of the adhesion between the epithelial cells of the stomach. This study aims to investigate the possibility of using $\beta$-catenin as a potential marker for gastric cancer and also as a predictive factor for the risk of developing gastric cancer in patients with gastritis and gastric ulcers.

\section{Materials \& Methods}

\subsection{Study subjects}

The study subjects were divided into four groups. The first group included 20 patients diagnosed with gastric cancer (12 males and 8 females) with an age range of (37-74 and 59-85 respectively), the second group included 20 patients diagnosed with gastric ulcer (10 males and 10 females) with an age range of (19-60 and 14-60 respectively), the third group included 30 patients diagnosed with gastritis (14 males and 16 females) with an age range of $(18-55$ and $17-40$ respectively) and the fourth group included 20 healthy individuals (10 males and 10 females) with an age range of $(22-41$ and $18-47$ respectively) serving as the control group. The patients enrolled in the present study were attending the educational oncology hospital, medical city, Baghdad, the endoscopy unit of gastroenterology and liver diseases hospital, medical city, Baghdad and the endoscopy unit of azadi teaching hospital, Duhok. This study was approved by the Department of Chemistry, College of Science, AlMustansiriyah University, Baghdad, Iraq, the Iraqi Ministry of Health and by the Research Ethics Committee of Duhok Directorate General of Health, Kurdistan Regional Government, Iraq.

\subsection{Exclusion criteria:}

Patients were excluded from the study if they had one or more of the following; previous or current chemotherapy, previous or current antibiotic or proton pump inhibitor (PPI) treatments, non-steroidal antiinflammatory drugs (NSAID), another type of cancer, a liver inflammation or other related liver diseases and gastrectomy. H. Pylori infected controls were excluded from the study.

\subsection{Samples collection}

Ten milliliters of blood were taken from the patients and healthy control. Blood samples were transferred into gel tubes and they were left for $(15-30)$ minutes at room temperature to clot. The obtained serum samples were stored at $\left(-20^{\circ} \mathrm{C}\right)$ till assayed. In addition, biopsy samples removed from the stomach of patients by the physicians performing the endoscopy were also collected for the histological and RUTs.

\subsection{Histological test and rapid urease test (RUT)}

Histological test was performed by specialized histologists in the laboratories of each hospital from which the biopsies were taken. RUT was performed in the endoscopy unit during the endoscopy procedure. A biopsy from the antrum were combined with a biopsy from the corpus and were placed on the RUT cassette and covered. After one hour, a color change (from yellow to pink) indicates a positive test. 


\subsection{Biochemical Analyses}

Serum $\beta$-catenin was measured by enzyme linked immunosorbent assay (ELISA) using Human $\beta$-catenin Elisa Kit purchased from (Mybiosource/ USA) following the manufacturer's directions. Anti-H. pylori IgG and IgA antibodies were measured by (ELISA) using Helicobacter IgG and Helicobacter IgA Elisa Kits purchased from (Demeditec/ Germany) following the manufacturer's directions. CEA and CA 19-9 tumor markers were measured by enzyme linked fluorescent assay (ELFA) using VIDAS CEA (S) and VIDAS CA 19-9 (199) kits purchased from (Biomerieux/ France) following the manufacturer's directions.

\subsection{Statistical Analyses}

Biochemical data were analyzed using SPSS (statistical package for social sciences) version 25 . T-Test was used to calculate mean \pm standard deviation (SD) and the $\mathrm{p}$ value.

\section{Results \& discussion}

\subsection{H. pylori detection}

The results showed that a total of 50 $(71.43 \%)$ patients were positive for $H$. pylori and $20(28.57 \%)$ were negative. The results of the control group were all negative. The patient was considered to be positive for the infection if at least two of the mentioned tests were positive. Tables (1) shows the $\mathrm{H}$. pylori infection status of the patients and controls confirmed by the histological test, RUT, IgA and IgG serological tests. Table (2) the shows results of the histological test, RUT, IgA and IgG serological tests.

\section{Table (1)}

Helicobacter pylori infection status of patients and control groups confirmed by the histological test, RUT and serological tests.

\begin{tabular}{|c|c||c||}
\hline Groups & $\begin{array}{c}\text { H. pylori } \\
\text { Positive } \\
\text { N (\%) }\end{array}$ & $\begin{array}{c}\text { H. pylori } \\
\text { Negative } \\
\text { N (\%) }\end{array}$ \\
\hline \hline $\begin{array}{c}\text { Gastric Cancer } \\
\text { Total N = 20 }\end{array}$ & $7(35)$ & $13(65)$ \\
\hline $\begin{array}{c}\text { Gastric Ulcer } \\
\text { Total N =20 }\end{array}$ & $13(65)$ & $7(35)$ \\
\hline $\begin{array}{c}\text { Gastritis } \\
\text { Total N = 30 }\end{array}$ & $30(100)$ & $0(0)$ \\
\hline $\begin{array}{c}\text { Control } \\
\text { Total N =20 }\end{array}$ & $0(0)$ & $20(100)$ \\
\hline
\end{tabular}

Table (2)

Results of the histological test, RUT, IgA and IgG serological tests.

\begin{tabular}{|c||c|c|}
\hline $\begin{array}{c}\text { Diagnostic } \\
\text { Method }\end{array}$ & $\begin{array}{c}\text { Positive } \\
\text { Cases N } \\
(\mathbf{\%})\end{array}$ & $\begin{array}{c}\text { Negative } \\
\text { Cases N } \\
(\mathbf{\%})\end{array}$ \\
\hline \hline Patients N =70 & $50(71.4)$ & $20(28.6)$ \\
\hline \hline Histology & $50(71.4)$ & $20(28.6)$ \\
\hline \hline RUT & $50(71.4)$ & $20(28.6)$ \\
\hline \hline IgG & $59(84.3)$ & $11(15.7)$ \\
\hline IgA & $11(15.7)$ & $59(84.3)$ \\
\hline Control N = 20 & $0(0)$ & $20(100)$ \\
\hline \hline IgG & $0(0)$ & $20(100)$ \\
\hline IgA & $0(0)$ & $20(100)$ \\
\hline
\end{tabular}

\subsection{Levels of Serum $\beta$-catenin}

Tables (3 and 4) show that there is a significant increase in the levels of $\beta$-catenin in the sera of patients diagnosed with gastric ulcer $(3.41 \pm 0.24 \mathrm{ng} / \mathrm{mL})$ and gastritis $(2.41 \pm$ $0.28 \mathrm{ng} / \mathrm{mL}$ ) compared to the control group $(1.54 \pm 0.29 \mathrm{ng} / \mathrm{mL})(\mathrm{p}<0.001)$, there is also a significant increase in the levels of $\beta$-catenin in sera of gastric cancer patients $(6.88 \pm 2.45$ $\mathrm{ng} / \mathrm{mL}$ ) in comparison to the controls as well as to the gastric ulcer and gastritis groups. There was a statistically non-significant change in the levels of CEA in the sera of gastric cancer patients $(3.96 \pm 1.93 \mathrm{ng} / \mathrm{mL})$ compared to the control group $(2.98 \pm 1.41$ $\mathrm{ng} / \mathrm{mL})(\mathrm{p}=0.094)$ and to the gastric ulcer $(3.77 \pm 1.64 \mathrm{ng} / \mathrm{mL})$ and gastritis patients $(3.62 \pm 1.42 \mathrm{ng} / \mathrm{mL})$. A non-significant change was also seen in the levels of CA 19-9 in sera of patients diagnosed with gastric cancer $(17.68 \pm 17.04 \mathrm{U} / \mathrm{mL})$ compared to the control group $(13.03 \pm 8.35 \mathrm{U} / \mathrm{mL})(\mathrm{p}=0.313)$ as well as to gastric ulcer $(14.40 \pm 9.13 \mathrm{U} / \mathrm{mL})$ and gastritis patients $(13.94 \pm 7.74 \mathrm{U} / \mathrm{mL})$. 
Table (3)

Levels of serum $\beta$-Catenin, CEA and CA 19-9 in patients and control groups.

\begin{tabular}{|c||c||c||c||c|c||c||c||}
\hline Parameters & $\begin{array}{c}\text { Gastric } \\
\text { Cancer (A) } \\
\text { Mean } \pm \text { SD } \\
(\mathbf{N}=\mathbf{2 0})\end{array}$ & $\begin{array}{c}\text { Gastric } \\
\text { Ulcer (B) } \\
\text { Mean } \pm \text { SD } \\
(\mathbf{N}=\mathbf{2 0})\end{array}$ & $\begin{array}{c}\text { Gastritis (C) } \\
\text { Mean } \pm \text { SD } \\
(\mathbf{N}=\mathbf{3 0})\end{array}$ & $\begin{array}{c}\text { Control (D) } \\
\text { Mean } \pm \text { SD } \\
(\mathbf{N}=\mathbf{2 0})\end{array}$ & $\begin{array}{c}\text { p-value } \\
\text { A vs D }\end{array}$ & $\begin{array}{c}\text { p-value } \\
\text { B vs D }\end{array}$ & $\begin{array}{c}\text { p-value } \\
\text { C vs D }\end{array}$ \\
\hline \begin{tabular}{c||c||c||c||c||}
$\boldsymbol{\beta}-$ Catenin \\
$(\mathbf{n g} / \mathbf{m L})$
\end{tabular} & $6.88 \pm 2.45$ & $3.41 \pm 0.24$ & $2.41 \pm 0.28$ & $1.54 \pm 0.29$ & $0.000 *$ & $0.000 *$ & $0.000 *$ \\
\hline \hline $\begin{array}{c}\mathbf{C E A} \\
(\mathbf{n g} / \mathbf{m L})\end{array}$ & $3.96 \pm 1.93$ & $3.77 \pm 1.64$ & $3.62 \pm 1.42$ & $2.98 \pm 1.41$ & 0.094 & 0.135 & 0.147 \\
\hline $\begin{array}{c}\mathbf{C A} \text { 19-9 } \\
(\mathbf{U} / \mathbf{m L})\end{array}$ & $17.68 \pm$ & $14.40 \pm 9.13$ & $13.94 \pm 7.74$ & $13.03 \pm 8.35$ & 0.313 & 0.642 & 0.708 \\
\hline
\end{tabular}

*significant at the level of $(\mathrm{p} \leq 0.05)$. SD; Standard deviation. N; number of tested samples.

Table (4)

Levels of serum $\beta$-Catenin, CEA and CA $19-9$ in patients'groups.

\begin{tabular}{|c|c|c|c|c|c|c|}
\hline Parameters & $\begin{array}{c}\text { Gastric } \\
\text { Cancer (A) } \\
\text { Mean } \pm \text { SD } \\
(\mathbf{N}=\mathbf{2 0}) \\
\end{array}$ & $\begin{array}{c}\text { Gastric } \\
\text { Ulcer (B) } \\
\text { Mean } \pm \text { SD } \\
(\mathbf{N}=\mathbf{2 0}) \\
\end{array}$ & $\begin{array}{c}\text { Gastritis } \\
(\mathrm{C}) \\
\text { Mean } \pm \text { SD } \\
(\mathbf{N}=\mathbf{3 0}) \\
\end{array}$ & $\begin{array}{c}\text { p-value } \\
\text { A vs B }\end{array}$ & $\begin{array}{c}\text { p-value } \\
\text { A vs C }\end{array}$ & $\begin{array}{c}\text { p-value } \\
\text { B vs C }\end{array}$ \\
\hline$\beta$-Catenin (ng/mL) & $6.88 \pm 2.45$ & $3.41 \pm 0.24$ & $2.41 \pm 0.28$ & $0.000 *$ & $0.000 *$ & $0.000 *$ \\
\hline CEA (ng/mL) & $3.96 \pm 1.93$ & $3.77 \pm 1.64$ & $3.62 \pm 1.42$ & 0.743 & 0.484 & 0.740 \\
\hline CA 19-9 (U/mL) & $17.68 \pm 17.04$ & $14.40 \pm 9.13$ & $13.94 \pm 7.74$ & 0.464 & 0.308 & 0.852 \\
\hline
\end{tabular}

*significant at the level of $(\mathrm{p} \leq 0.05)$. SD; Standard deviation. N; number of tested samples.

From Table (5), it can be observed that there is a significant increase in the levels of $\beta$ catenin in sera of gastric cancer patients infected with $H$. pylori $(9.67 \pm 0.27 \mathrm{ng} / \mathrm{mL})$ compared to uninfected gastric cancer patients $(5.49 \pm 1.93 \mathrm{ng} / \mathrm{mL})$. There is also a significant increase in $\beta$-catenin levels in the sera of gastric ulcer patients infected with $H$. pylori $(3.56 \pm 0.15 \mathrm{ng} / \mathrm{mL})$ compared to uninfected gastric ulcer patients $(3.13 \pm 0.09$ $\mathrm{ng} / \mathrm{mL}$ ). There was no significant difference in the levels of CEA and CA 19-9 tumor markers between $H$. pylori infected and $H$. pylori uninfected patients.

Table (5)

Levels of serum $\beta$-Catenin, CEA and CA 19-9 in H. Pylori infected patients.

\begin{tabular}{|c|c|c|c|c|c|c|}
\hline \multirow{2}{*}{ Parameters } & \multicolumn{2}{|c|}{ Gastric Cancer $($ Mean \pm SD) } & \multirow{2}{*}{ p-value } & \multicolumn{2}{|c|}{ Gastric Ulcer (Mean \pm SD) } & \multirow{2}{*}{ p-value } \\
\hline & $\mathrm{HP}+(\mathrm{N}=7)$ & $H P-(N=13)$ & & $\mathrm{HP}+(\mathrm{N}=13)$ & $\mathrm{HP}-(\mathrm{N}=7)$ & \\
\hline$\beta$-Catenin $(\mathrm{ng} / \mathrm{mL})$ & $9.67 \pm 0.27$ & $5.49 \pm 1.93$ & $0.000^{*}$ & $3.56 \pm 0.15$ & $3.13 \pm 0.09$ & $0.000^{*}$ \\
\hline CEA (ng/mL) & $3.90 \pm 1.02$ & $3.99 \pm 2.27$ & 0.929 & $3.56 \pm 1.18$ & $4.15 \pm 2.21$ & 0.472 \\
\hline CA 19-9 (U/mL) & $16.66 \pm 11.73$ & $18.14 \pm 19.29$ & 0.853 & $14.56 \pm 9.45$ & $14.07 \pm 8.49$ & 0.912 \\
\hline
\end{tabular}

HP: H. pylori. *significant at the level of $(\mathrm{p} \leq 0.05)$. SD; Standard deviation. N; number of tested samples.

In this research, the levels of $\beta$-Catenin protein were measured in three groups of gastric related diseases. Levels of this protein might give an indication for the integrity of the E-cadherin- $\beta$-catenin complex and thus the integrity of the cellular adhesions. The reason behind choosing these gastric related diseases is that all of them involve defects in the gastric mucosa and the cells lining the stomach
$[20,21]$. Such defects alongside the presence of $H$. pylori infection cause damage to the cellular adhesions, more precisely the AJs, this would subsequently lead to the dissociation of the E-cadherin- $\beta$-catenin complex and to the accumulation of $\beta$-catenin in the cytoplasm [22]. It appears that this free $\beta$-catenin can leak to the general circulation and this may represent a possible explanation for the 
elevated levels of this protein in the patients' groups. The connection between $H$. pylori and the event of gastric malignancy presents a model of malignancy advancement as a result from a bacterial infection and inflammation. The instruments whereby $H$. pylori fundamentally builds the danger of gastric malignancy are more obvious in the intestinal type gastric malignant growth, which advances in a very much characterized arrangement of histological advances. The advancement of this sort is set apart by a moderate movement, starting with $H$. pylori then subsequently evolving to gastritis, which happens in every single tainted person. Affected by host and environmental factors, gastritis may thus develop into intestinal metaplasia. In specific people, the metaplastic epithelium experiences additional genomic changes, bringing about dysplasia and, at last, in adenocarcinoma $[23,24]$. The results of the present study suggest that $H$. pylori infection can further increase the damage to the cellular adhesions and the AJs and subsequently increasing the risk of these gastric related diseases, especially gastric cancer, this was clearly reflected in the higher levels of serum $\beta$-catenin in patients infected with $H$. pylori compared to the uninfected patients.

To our best knowledge and after an extensive literature search, we could only find a single Chinese study that described the levels of serum $\beta$-catenin in stomach cancer, the authors assessed a variety of proteins as serum biomarker panels in 228 gastric cancer patients and 190 controls and their results showed that there was a significant increase in the levels of $\beta$-catenin in sera of gastric cancer patients [19], these finding were similar to the results our present study. However, no attempts have been made so far to measure the serum levels of $\beta$-catenin in gastritis and gastric ulcer patients.

\subsection{Levels of serum CEA and CA 19-9 tumor markers}

As it was seen in tables (3 and 4), there was no significant difference in the concentrations of CEA and CA 19-9 tumor markers in gastric cancer patients compared to the control group. In addition, the concentrations of these tumor markers were also non-significantly changed in gastritis and gastric ulcer patients. There was also no significant difference in the concentrations of these tumor markers in patients infected with H. pylori compared to uninfected patients. The results of the present study are in accordance to many of the previous studies that reported similar results. Previous studies reported that CEA and CA 19-9 markers are advantageous tools for metastasis and recurrence of malignancies as well as for assessing the effectiveness of chemotherapy and prognosis in gastric malignancy $[25,26]$. However, CA 19-9 and CEA as indicated by earlier studies are not helpful for the finding of early gastric malignancy [27]. Elevated concentrations are also seen in different tumors and in some nonmalignant conditions, for example, gastritis, gastric ulcer, duodenitis and esophagitis [28 - 30]. The consequences of certain investigations question the advantage of CA 19-9 and CEA even as monitoring or observing markers in gastric cancers [31 - 34].

\section{Conclusion}

$\beta$-catenin protein may serve as a potential biomarker in the diagnosis of gastric cancer cases of this study. In the present study cases, CA 19-9 and CEA were not reliable nor accurate in the screening for gastric cancer. $H$. pylori possesses a marked influence on the cellular adhesions between the stomach cells which supports the role of this bacterium in the pathogenesis of gastric related diseases, especially gastric cancer. Gastritis and gastric ulcer patients might be at a higher risk for developing gastric cancer.

\section{Acknowledgements:}

The work was supported by the Department of Chemistry and Department of Biology in the College of Science at Mustansiriyah University in Baghdad, Iraq.

\section{References}

[1] Takahiro, S.; Hiroyuki, M.; Norihiko, W.; Tsutomu, C. "Molecular Pathogenesis of Helicobacter Pylori-Related Gastric Cancer"; Gastroenterol. Clin. North Am. 44, 625-638, 2015.

[2] Ingrid, P. V.; Rachel, S. V.; Han, J. V.; Liesbeth, S.; Wendy, A. Z.; Marleen, K.; 
Jan, L.; Anna, J.; Urszula, T.; Cora, M. A.; Van-Hest, L. P.; Pinheiro, H.; Oliveira, C.; Jhangiani, S. N.; Muzny, D. M.; Gibbs, R. A.; Lupski, J. R.; de-Ligt, J.; Vissers, L. E.; Hoischen, A.; Gilissen, C.; vande-Vorst, M.; Goeman, J. J.; Schackert, H. K.; Ranzani, G. N.; Molinaro, V.; Gómez, G. E.; Hes, F. J.; Holinski-Feder, E.; Genuardi, M.; Ausems, M.; Sijmons, R. H.; Wagner, A.; vander-Kolk, L. E.; Bjørnevoll, I.; Høberg-Vetti, H.; van-Kessel, A. G.; Kuiper, R. P.; Ligtenberg, M. J.; Hoogerbrugge, N. "Unraveling genetic predisposition to familial or early onset gastric cancer using germline whole exome sequencing"; Eur. J. Hum. Genet. 25, 12461252, 2017.

[3] Lauren, P. "The two histological main types of gastric carcinoma: diffuse and socalled intestinal-type carcinoma. An attempt at a histo-clinical classification"; Acta. Pathol. Microbiol. Scand. 64, 31-49, 1965.

[4] Magdalena, C.; Zuzanna, K.; Weronika, G.; Bujana, A.; Paweł, S. "Host pathogen interactions in Helicobacter pylori related gastric cancer"; World J. Gastroenterol. 23, 1521-1540, 2017.

[5] Bagheri, N.; Azadegan-Dehkordi, F.; Rahimian, G.; Hashemzadeh-Chaleshtori, M.; Rafieian-Kopaei, M.; Kheiri, S.; Gholipour, A.; Shirzad, H. "Altered Th17 Cytokine Expression in Helicobacter pylori Patients with TLR4 (D299G) Polymorphism"; Immunol. Invest. 45, 161 171, 2016.

[6] Xu, G.; Yan, Z.; Hermann, B. "Associations of Helicobacter pylori infection and chronic atrophic gastritis with accelerated epigenetic ageing in older adults"; Br. J. Cancer. 117, 1211-1214, 2017.

[7] Amin, T. B.; Johannes, G. K. "Management of Helicobacter pylori Infections"; BMC Gastroenterol. 16, 1 - 4, 2016.

[8] Farzaneh, J.; Safar, F.; Mohammad, H. S.; Zoya, H.; Rana, Y.; Nazli, S. "Comparative Evaluation of RUT, PCR and ELISA Tests for Detection of Infection with Cytotoxigenic H. pylori"; Adv. Pharm. Bull. 6, 261-266, 2016.
[9] Tomas, V.; George, H.; Konrad, B. "The many faces and functions of b-catenin"; EMBO J. 31, 2714-2736, 2012.

[10] Malinova, T. S.; Huveneers, S. "Sensing of Cytoskeletal Forces by Asymmetric Adherens Junctions"; Trends Cell Biol. 28, 328-341, 2018.

[11] Pinho, S. S.; Carvalho, S.; Marcos-Pinto, R.; Magalhaes, A.; Oliveira, C.; Gu, J.; Dinis-Ribeiro, M.; Carneiro, F.; Seruca, R.; Reis, C. A. "Gastric cancer: adding glycosylation to the equation"; Trends Mol. Med. 19, 664-676, 2013.

[12] Kikuchi, A.; Yamamoto, H.; Sato, A.; Matsumoto, S. "New insights into the mechanism of Wnt signaling pathway activation"; Int Rev Cell Mol Biol. 291, 2171, 2011.

[13] Miguel, A. C. "Role of the Wnt/ $\beta$-catenin pathway in gastric cancer: An in-depth literature review"; World J Exp Med. 5, 84102, 2015.

[14] Sergio, N.; Jose, C. M.; Carlos, L.; Raquel, S.; Faitima, C.; Manuel, S. "Patterns of -Catenin Expression in Gastric Carcinoma: Clinicopathological Relevance and Mutation Analysis"; Int J Surg Pathol $11,1-9,2003$

[15] Thiele, A.; Wasner, M.; Muller, C.; Engeland, K.; Hauschildt, S. "Regulation and possible function of beta-catenin in human monocytes"; J Immunol. 167, 67866793, 2001.

[16] Tian, J.; Xu, X. J.; Shen, L.; Yang, Y. P.; Zhu, R.; Shuai, B.; Zhu, X. W.; Li, C. G.; Ma, C.; Lv, L. "Association of serum Dkk-1 levels with beta-catenin in patients with postmenopausal osteoporosis"; J Huazhong Univ Sci Technol Med Sci. 35, 212-218, 2015.

[17] Gaudio, A.; Privitera, F.; Battaglia, K.; Torrisi, V.; Sidoti, M. H.; Pulvirenti, I.; Canzonieri, E.; Tringali, G.; Fiore, C. E. "Sclerostin levels associated with inhibition of the Wnt/beta-catenin signaling and reduced bone turnover in type 2 diabetes mellitus"; J Clin Endocrinol Metab. 97, 3744-3750, 2012.

[18] Zekri, A. R.; Bahnassy, A. A.; Alam, E. H.; Morsy, H. M.; Shaarawy, S.; Moharram, N. Z.; Daoud, S. S. "Serum levels of betacatenin as a potential marker for genotype 
4/hepatitis C-associated hepatocellular carcinoma"; Oncol Rep. 26, 825-831, 2011.

[19] Tong, W.; Fei, Y.; Liang, H.; Lifeng, C.; Miao, C.; Yuan, H.; Wei, L.; Jing, J.; David, Y. Z.; Jian, S. "Serum biomarker panels for diagnosis of gastric cancer"; Onco Targets Ther. 9, 2455-2463, 2016.

[20] Jacek, M.; Bartłomiej, Z.; Paweł, K.; Adam, N.; Barbara, G.; Magdalena, B.; Agnieszka, E.; Magdalena, Z.; Beata, M.; Jolanta, S. "Gastritis - facts and doubts"; Gastroenterol. Rev. 11, 286-295, 2016.

[21] Hunt, R. H.; Camilleri, M.; Crowe, S. E.; El-Omar, E. M.; Fox, J. G.; Kuipers, E. J.; Malfertheiner, P.; McColl, K. E.; Pritchard, D. M.; Rugge, M.; Sonnenberg, A.; Sugano, K.; Tack, J. "The stomach in health and disease"; Gut. 64, 1650-1668, 2015.

[22] Backert, S.; Schmidt, T. P.; Harrer, A.; Wessler, S. "Exploiting the Gastric Epithelial Barrier: Helicobacter pylori's Attack on Tight and Adherens Junctions"; Curr. Top. Microbiol. Immunol. 400, 195226, 2017.

[23] Lydia, E. W.; Richard, M. P.; Keith, T. W. "Helicobacter pylori and Gastric Cancer: Factors That Modulate Disease Risk"; Clin. Microbiol. Rev. 23, 713-739, 2010.

[24] Manuel, A. V.; Jimena, C.; Alejandro, H. C.; Andrew, F. Q. "Helicobacter pyloriinduced inflammation and epigenetic changes during gastric carcinogenesis"; World J. Gastroenterol. 21, 12742-12756, 2015.

[25] Wang, Q.; Yang, Y.; Zhang, Y. P.; Zou, Z.; Qian, X.; Liu, B.; Wei, J. "Prognostic value of carbohydrate tumor markers and inflammation-based markers in metastatic or recurrent gastric cancer"; Med. Oncol. 31, 289-299, 2014.

[26] Jing, J.; Xu, X.; Du, L.; Tian, B.; Sun, T.; Zhao, X.; Han, C. "Clinical assessment and prognostic evaluation of tumor markers in patients with gastric cancer"; Int. J. Biol. Markers. 28, 192-200, 2013.

[27] Feng, F.; Tian, Y.; Xu, G.; Liu, Z.; Liu, S.; Zheng, G.; Guo, M.; Lian, X.; Fan, D.; Zhang, H. "Diagnostic and prognostic value of CEA, CA19-9, AFP and CA125 for early gastric cancer"; BMC Cancer. 17, 737-743, 2017.
[28] Ozgur, T. "The diagnostic value of tumor markers and endoscopy in patients with gastric disorders"; Arch. Clin. Exp. Surg. 4, 74-78, 2015.

[29] Xin, A.; Pei-Rong, D.; Xiao-Juan, X.; Zhi-Qiang, W.; Feng-Hua, W.; Fen, F.; Wen-Qi, J.; You-Jian, H.; Rui-Hua, X.; YuHong, L. "Carcinoembryonic antigen surge in metastatic Colorectal cancer patients responding to irinotecan combination chemotherapy"; Biomarkers. 15, 243-248, 2010.

[30] Cătălina, D.; Mădălina, I.; Gaudia, M. A.; Laura, V.; Daniel, O. C.; Raluca, S. C. "Tumor markers in gastroenterology: useful or useless"; Rom. J. Mil. Med. 119, 17 -22, 2016.

[31] Polat, E.; Duman, U.; Duman, M.; Derya, P. K.; Akyuz, C.; Fatih, Y. N.; Uzun, O.; Akbulut, S.; Birol, B. E.; Yol, S. "Preoperative serum tumor marker levels in gastric cancer"; Pak. J. Med. Sci. 30, 145149, 2014.

[32] Ohtsuka, T.; Sato, S.; Kitajima, Y.; Tanaka, M.; Nakafusa, Y.; Miyazaki, K. "False-positive findings for tumor markers after curative gastrectomy for gastric cancer"; Dig. Dis. Sci. 53, 73-79, 2008.

[33] Hasbahceci, M.; Fu, M.; Kunduz, E.; Guler, M.; Unver, N.; Akcakaya, A. "Use of serum and peritoneal CEA and CA19-9 in prediction of peritoneal dissemination and survival of gastric adenocarcinoma patients: are they prognostic factors?"; Ann. R. Coll. Surg. Engl. 100, 257-266, 2018.

[34] Junxiu, Y.; Shuguang, Z.; Bingbo, Z. "Differences and correlation of serum CEA, CA19-9 and CA72-4 in gastric cancer"; Mol. Clin. Oncol. 4, 441-449, 2016. 